\title{
Undiagnosed Hypertension and Associated Factors among Adult Dwellers in Hawela Tula Sub City, Hawassa, Southern Ethiopia: A Community Based Cross-sectional Study
}

\section{Demelash Wachamo ( $\nabla$ demmenew1@gmail.com )}

Hawassa University College of Medicine and Health Sciences https://orcid.org/0000-0001-6412-422X

\section{Endrias Markos}

Hawassa University College of Medicine and Health Sciences

\section{Dereje Geleta}

Hawassa University College of Medicine and Health Sciences

\section{Research article}

Keywords: Undiagnosed hypertension, Health-seeking behavior, Hawassa city, Ethiopia

Posted Date: October 2nd, 2019

DOl: https://doi.org/10.21203/rs.2.15583/v1

License: (c) (1) This work is licensed under a Creative Commons Attribution 4.0 International License.

Read Full License 


\section{Abstract}

Introduction Hypertension is a common public health problem and often goes unnoticed and can lead to a stroke or heart attack. It contributes to the high burden of cardiovascular disease, premature mortality, reduced quality of life and high costs to the health care system, especially in low and middle-income countries. Therefore, this study aimed to assess the prevalence of undiagnosed hypertension and influencing factors with health-seeking behaviour.Method A community-based cross-sectional study was conducted on 390 randomly selected adults in Hawela Tulla Sub-city, Hawassa, southern Ethiopia from February to June, 2019. Data was collected by pre-tested questionnaires and physical measurements of weight, height and blood pressure were collected through standardized procedures adapted from WHO STEPS survey tools. Data entry and analyzed for descriptive and logistic regression models by SPSS $v .23$. The result declared as statistically significant at $p<0.05$. Result The prevalence of the undiagnosed hypertension among the respondents was $12.3 \%$. The male [AOR=3.70, 95\% Cl:1.64-8.32] than female contributing. Family history of hypertension had [AOR 3.69, 95\% Cl: 1.31-10.34], being physical inactive [AOR 3.21, 95\% Cl: 1.50- 6.84], salty food consumer [AOR 3.67, 95\% Cl:1.26-10.64], BMI $25 \mathrm{Kg} / \mathrm{m} 2$ and above [AOR 3.06, 95\% Cl:1.41-6.65] and not seek health care for some early hypertensive symptoms without serious illness [AOR 4.58, 95\% Cl: 1.85-11.32] when compared to their counterparts, were found to be determinant factors for undiagnosed hypertension. Conclusions and Recommendation The prevalence of undiagnosed hypertension found to be prevalent and calls for intervention. Health officials need to consider integrating the prevention and control of hypertension at the community level. The clinicians need to intervene on unhealthy lifestyles, by promoting healthy practices and health-seeking behavior to prevent undiagnosed hypertension.

\section{Background}

Hypertension already affects one billion people worldwide, leading to heart attacks and strokes [1]. It rarely manifests symptoms in the early stages and many people remain undiagnosed and invisible killer that rarely causes symptoms that may be late to successfully control their illness over the long term [2].

Elevated BP is the leading contributor to premature death, accounting for almost 10 million deaths in 2015, 4.9 million due to ischaemic heart disease and 3.5 million due to stroke [3]. The prevalence of hypertension in Africa $46 \%$ among WHO regions [4], $25 \%$ is the percentage of deaths under 60 that are attributable to hypertension in Africa [5]. The majority of African countries cannot afford the high costs of treatment with many other competing health priorities and limited resources [6].

Ethiopia as a developing country, there are economic development, industrialization, nutrition transition and globalization that lead to a rapid change in lifestyles that paramount the risk of hypertension [7]. However, WHO is working hard to achieve SDG target 3.4 to reduce by one- third premature mortality from NCDs through prevention and treatment at 2030 [8]. There was a high prevalence of hypertension probably indicating a hidden epidemic in this community [9]. The study reports of Ethiopia NCD STEPS, 2016 indicate that $76.6 \%$ of the total population never been measured for blood pressure per year. Some 
studies indicate there was a high prevalence of undiagnosed hypertension among working-age groups that were major health problem which requires urgent action $[7,10]$. There is a gap in recording and reporting, no study reports show that undiagnosed hypertension in the study area. This study indicates there are hidden epidemics of undiagnosed hypertension, which associated with a sedentary lifestyle, dietary, and not seeking modern health care. This is important for researchers, clinicians, and health planners.

\section{Methods}

The source population was all resident households of 4 urban and 8 rural kebele city (the smallest administrative units in Ethiopia) dwellers in Hawela Tula sub-city. While all randomly selected adults from selected households in urban and rural kebele at Hawela Tula sub-city of Hawassa city administration during the study period was the study population. The study was conducted on 390 calculated by a single population proportion formula and $10 \%$ possible non-response rate. A multistage random sampling technique. In the first stage, five out of 12 kebeles were selected by simple random sampling technique. In the second stage, the sample size was proportionally allocated. In the last stage, only one random selected eligible person was interviewed. The age of 18 years or older adults and had no visit to any health facility in 12 last months for BP check before the study period was included. All adults who, are unable to be interviewed, apparently with the history of any major illness, known hypertensive, who are taking anti-hypertensive treatment, pregnant women were excluded from the study.

\section{Data collection method and instruments}

Data were collected by pre- tested structured questionnaires and physical measurements of weight, height and blood pressure were collected through standardized procedures adapted from a modified WHO STEPwise approach to surveillance- Instrument v.3.1 [11]. The questionnaire was pretested on $5 \%$ of the study participants found outside of the study area and modifications were made based on the findings. Data collectors were five clinical nurses supervised by investigators. Training and practical demonstrations on interview techniques and measurement procedures were given to data collectors for two consecutive days assessed for competency.

Data entry, cleaning, and analysis were done by SPSS V. 23. All factors with a p-value $<0.2$ in the bivariate logistic regression analysis were a candidate to the multivariable model to control confounding effects. The Hosmer -Lemeshow goodness-of-fit statistic was used to assess whether the necessary assumptions for the application of multiple logistic regression are fulfilled. Odds ratios (OR) with $95 \%$ confidence intervals $(\mathrm{Cl})$ were calculated. Finally, $\mathrm{p}$-value $<0.05$ declared a significant association.

Ethical clearance was obtained from Hawassa university college of medicine and health sciences ethical review committee, support letter was also requested from the SNNPR, Hawassa city \& Hawela Tulla Subcity health bureau. All participants informed well about purpose, risk and benefit, and confidentiality. Participation was fully voluntary and written informed consent (verbal consent for who cannot read and write respondent) was obtained from each participant. 
Undiagnosed hypertension: was defined as SBP $140 \mathrm{mmHg}$ and above, and/or DBP $90 \mathrm{mmHg}$ and above, without previous history or anti-hypertensive treatment during survey diagnosis [12].

Physical inactivity- Who involved in combination of moderate and vigorous activities for less than 10 $\mathrm{min} /$ day, or $30 \mathrm{~min}$ and above of moderate dynamic exercise on 5-7 days per week [13].

BMI interpretation: overweight/obesity - a body mass index (BMI) $25.0 \mathrm{~kg} / \mathrm{m}^{2}$ and above.

Harmful alcohol use: who had consumed alcohol consumption more than 14 units/week for men and more than 8 units/week for women in the last 12 months. Unit of alcohol $=\mathrm{vol}$ (in $\mathrm{ml}$ ) X \% alcohol/ 1000 . For local alcoholic beverages: Tella (4\%), Tej (10\%) and arake (40-45\%) alcohol content, (as Glass $250 \mathrm{ml}$ and bottle as $330 \mathrm{ml}$ ) [12].

Cigarette smokers: who had used cigarette smokers form of tobacco in the last 30 days [14].

Low consumption of fruits and vegetables: Fewer than 5 servings of fruit and/or vegetables per day [7]. (1serving =one orange/apple/banana or three tablespoons of cooked vegetables).

\section{Results}

A total of 383 participants (aged 19-61 years, with the mean ( $\pm S D)$ age of $33.48( \pm 10.30)$ were interviewed yielding a response rate of $98.21 \%$. Nearly half of the studied participants $196(51.2 \%)$ were male and $191(49.9 \%)$ in the age category of $30-49$ years old. The majority of $320(83.6 \%)$ were married and $258(67.4 \%)$ were rural resident. Regarding ot educational stus, $56(14.6 \%)$ have no formal education and 177 (46.2\%) had a primary school, while only 150 (39.2\%) had high school and above education. The occupation of the participants 137 (35.8\%) were farmer and 144 (37.6\%) were employed. The monthly income of the households, 182 (47.5\%) earned between 450 - 1920 ETB, and 201 (52.5\%) earned more than 1920 ETB (Table 1).

\section{Behavioral related characteristics}

From the total study participants, $27(7.0 \%)$ were use any tobacco products, among this $14(3.7 \%)$ were current cigarette smokers. The prevalence of Khat chewing was $48(12.5 \%)$, among this $16(33.3 \%)$ were chew daily. Regarding to alcohol consumption, 71 (18.5\%) were ever drunk alcohol, 63 (16.4\%) were currently drinking alcohol (last 30 days). Their favourate alcohol was maily locally prepared and reported as, 25 (39.7\%) drink Tejji, 21 (33.3\%) drink Beer, 9 (14.3\%) Areke and other local drinks and 8 (12.7\%) Wine. The prevalence of harmful alcohol consumption was calculated as $37(9.7 \%)$ among adults (Fig 1$)$.

Physical Activities 
The vigorous activities $\geq 10$ minute/day, 115 (30.0\%) sawing hardwood, 177 (46.2) ploughing, 26 (6.8\%) playing football and $10(2.6 \%)$ weight lifting $>20 \mathrm{~kg}$ as daily physical activities. The study participants involved in moderate activities atleast 10 minute/day were mainly 72 (18.8\%) washing clothes by hand, 126 (32.9\%) drawing (Fetching) water and 281 (73.4\%) walking. The prevalence of sedentary life style or physically inactive was 148 (38.6\%) (Table 2).

Dietary Practice and BMI of respondents

The two-third 298 (77.8\%) of the participants eat foods containing oil and fat, regularly, whereas, 360 $(94.0 \%)$ were consume vegetables. The majority of 366 (95.6\%) were consume $<5$ servings of fruit and/or vegetables on average/day. The prevalence of overweight/obesity was $84(21.9 \%)$.

Health seeking behaviour

The majority, 357 (93.2\%) were ever had BP measurement. Regarding to risk of hypertension, 106 (27.7\%) consuming high salt, and $40(10.4 \%)$ alcoholism and fat were mainly identfied as a risk for getting hypertension. The study participants who did not know about hypertension, 152 (39.7\%) symptoms, 123 (32.1\%) prevention options and $160(41.8 \%)$ complication of hypertension. Only $108(28.2 \%)$ had agree to seek health care for some hypertensive symptoms without serious illness. The main reasons for not seeking health, $103(35.8 \%)$ due to shortage of money and $126(43.8 \%)$ illness was not severe.

Prevalence of Undiagnosed Hypertension

The prevalence of undiagnosed hypertension was $47(12.3 \%)$ at $95 \% \mathrm{Cl}(9.3,15.8)$. out of this $24(51.1 \%)$ were only systolic and 23 (48.9\%) were both systolic \& diastolic hypertension (Fig 2).

Associated Factors for Undiagnosed Hypertension

In the multivariate analysis sex of respondent, occupation, family history of hypertension, physical inactive, consume high salty food, $\mathrm{BMI}(\mathrm{Kg} / \mathrm{m} 2)$ and health seeking behaviour were remains as determinant for prevalence of undiagnosed hypertension. Regarding to the modifiyable risk factors, the study participants who were physical inactive was approximtely 3 times more likely exposed to had undiagnosed hypertension with [AOR 3.21, 95\% Cl: 1.50, 6.84] than compared with more physical active. More salty food consumer [AOR 3.67, 95\% Cl:1.26, 10.64], BMI $25 \mathrm{Kg} / \mathrm{m} 2$ and above or over weight/obesity had about 3 times more exposed to develop undiagnosed hypertension with [AOR 3.06, $95 \% \mathrm{Cl}: 1.41,6.65]$ when compared to their counterparts. The prevalence of undiagnosed hypertension was high among who are not seek health care for some early hypertensive symptoms without serious illness with [AOR 4.58, 95\% Cl: 1.85, 11.32] when compared to who seek earlier (Table 3).

\section{Discussion}

This population-based cross-sectional study revealed that, the prevalence of undiagnosed hypertension was $12.3 \%$, [95\% Cl: 9.3-15.8] among study population. This study result was consistent with the study 
findings in Gulele sub-city, Addis Ababa city, Ethiopia reported (13.25\%) [15] and in Gondar city, NorthWest Ethiopia (10.47\%) [9]. Another study from Vietnam reported (14.1\%) [16], India (10.1\%) [7], 10.0\% in North Indian state of Punjab [17].

This study result slightly lower when compared with the study conducted in Bedele Town, Southwest Ethiopia (16.9\% ) [18], and in Aksum town, northern Ethiopia (16.5\% ) [19] and in Addis Ababa, Ethiopia (25\%) [20]. Onother hand, it was higher from Gilgel Gibe (7.5\%) [21] and Durame Town, Southern Ethiopia $(8.96 \%)$ [22]. This discrepancy may due to this study is considered majorly urban setting whereas the former studies not included urban and rural settings and other difference on study population in socio demographic difference like: the age difference in the study population more than 18 included on this study while other studies included adult population aged above 30 year.

The male participants were more likely to had undiagnosed hypertension than female contributing. Which was similar with study conducted in North India [17] and Durame Town [22]. This may due to related with ability to afford fatty food, sugar, cigarette smoking, alcohol and being physical inactivity due to utilization of vehcle. The prevalence of undiagnosed hypertension was high among adults who had family history of hypertension. This result inline with study report from Jigjiga city of eastern Ethiopia [23], and Gondar, Northwest Ethiopia [9]. This may due to variability in blood pressure might explained by genetic factors. Physical inactive study participants were more likely exposed to had undiagnosed hypertension. This was consistent with study findings from Gondar city in Ethiopia [24], Addis Ababa Ethiopia [25] and Kerala, India [26]. This may due to rapid growth of urbanization, in urban areas using taxis, motor cycles to move from place to place may affect the mobilization of dwellers.

The prevalence of undiagnosed hypertension was high among more salty food consumer than their counterpart. This study result inline with North India [17] and in Jigjiga city of eastern Ethiopia [23]. This agreement may due to high salt containing foods increase high absorption of water and increase blood volume that responsible for high blood pressure. Being over weight/obesity was more likely exposed to develop undiagnosed hypertension when compared to their counterparts. This was agree with study findings from Gondar city in Ethiopia [24], Durame Town, Southern Ethiopia [22], Addis Ababa Ethiopia [27] and Kerala, India [26]. The prevalence of undiagnosed hypertension was high among not seek health care for some early hypertensive symptoms. This was consistent with study findings from south India [28] and Nairobi Kenya [29] states failure to seeking health services increase prevalence of undiagnosed hypertension. This may due to seek health care for some hypertensive symptoms without serious illness not common due to lack of money, health related information about prevention, early symptoms and health benefits of early modern health care seeking benefit.

Despite to other study findings, there was no another socio demographic and other behaviour al factors had statistically significant association with undiagnosed hypertension on this study. This may be due to the minimum prevalence of these factors in the community studied.

This study result shows there was high prevalence of undetected hypertension among adults in selected house hold at Hawela Tulla Sub-city. Which related to occurred irrespective of the income status and due 
to low level of health seeking behaviour of the study participants. This study findings suggest for we need more attention on different strategies to address early detection for better prevention, evaluation, and management of high blood pressure in adults.

This study has potential limitations as the study is cross-sectional in design; it neither represents seasonal variation of nutritional outcomes nor establishes causal relationship. There was no pregnancy test for to female participants and early pregnancy that can not be noticed by participants and data collectors was difficult to differentiate. For harmful alcohol consumption calculation majority reports maily locally prepared alcohol and which was hard to estimate the concentration.

\section{Conclusions}

This study result shows there was high prevalence of undiagnosed hypertension when compared with other studies and indicates there is hidden epidemic in this population. Being male, having family history of hypertension, being physically inactive, high salty food consumption, and over weight/obesity and not seeking modern health care for some hypertensive symptoms without serious illness were associated with undiagnosed hypertension and statistically significant when compared to their counterparts.

\section{Abbreviations}

DBP= Diastolic Blood Pressure, ETB= Ethiopian Birr, FDRE= Federal Democratic Republic of Ethiopia, $\mathrm{mmHg}=$ Millimeters of Mercury, NCDs= Non-Communicable Diseases, SBP= Systolic Blood Pressure, SNNP= Southern Nations, Nationalities, and People, SPSS= Statistical Package for Social Science, WHO= World Health Organization

\section{Declarations}

\section{Consent for publication}

Not applicable.

\section{Availability of data and materials}

There is no remaining data and materials, all information is clearly presented in the main manuscript.

\section{Competing interests}

The authors declare that they have no conflict of interests.

\section{Funding}

No funding was obtained.

\section{Authors' contributions}


DW wrote the proposal, participated in data collection, analyzed the data and drafted the paper. EM and DG approved the proposal with some revisions, participated in data collection, analysis and manuscript writing. authors read and approved the final manuscript.

Acknowledgements

The authors would like to thank Hawassa University, College of Medicine and Health Science for ethical approival. We would like to thanks to Hawassa city administration health bureau and Hawela Tula sub city for their cooperation on providing, material support, information and support letter. The authors are also grateful to the all data collectors and study participants for their valuable contribution.

\section{References}

1. Forouzanfar $\mathrm{M} \mathrm{H}$, Liu P, Roth $\mathrm{G}$ A, et al. Global burden of hypertension and systolic blood pressure of at least 110 to $115 \mathrm{~mm}$ hg, 1990-2015. JAMA. 2017;317(2):165-82.

2. World Health Organization, A Global Brief on Hypertension, Monitoring the impact of action to tackle hypertension. 20 Avenue Appia, 1211 Geneva 27, Switzerland: WHO Press, 2013.

3. Williams B, Mancia G, Spiering W, Rosei E A, Azizi M, et al. 2018 ESC/ESH Guidelines for the management of arterial hypertension. Kardiologia Polska (Polish Heart Journal). 2019;77(2):71-159.

4. World Health Organization (WHO). Global health observatory (GHO) data: raised blood pressure. 2016.

5. Mathers C, Stevens G, Mascarenhas M. Global health risks: mortality and burden of disease attributable to selected major risks. Geneva, Switzerland: World Health Organization; 2009.

6. Palafox B, McKee M, Balabanova D, AlHabib K F, Avezum A, Jr., et al. Wealth and cardiovascular health: a cross-sectional study of wealth-related inequalities in the awareness, treatment and control of hypertension in high-, middle- and low-income countries. International journal for equity in health. 2016;15(1):199-.

7. Undavalli V K, Praveen M, Narni H. Prevalence of undiagnosed hypertension: a public health challenge. International Journal Of Community Medicine And Public Health. 2018;5(4):1366-70.

8. Norheim O F, Jha P, Admasu K, Godal T, Hum R J, et al. Avoiding $40 \%$ of the premature deaths in each country, 2010-30: review of national mortality trends to help quantify the UN Sustainable Development Goal for health. The Lancet. 2015;385(9964):239-52.

9. Awoke A, Awoke T, Alemu S, Megabiaw B. Prevalence and associated factors of hypertension among adults in Gondar, Northwest Ethiopia: a community based cross-sectional study. BMC Cardiovascular Disorders. 2012;12(1):113.

10. Gerensea H, Teklay H. Trend of hypertension morbidity and mortality in Tigray Region from 2011 to 2015, Tigray, Ethiopia. BMC research notes. 2018;11(1):375-

11. A Survey on Prevalence of NonCommunicable Diseases (NCDs) and Their Risk Factors among Adults in Mekelle and Kilte-Awlaelo, Ethiopia. 2018. 
12. Guidelines on Clinical and Programmatic Management of Major Non-Communicable Diseases. In: survey NCDNn, editor. Addis Ababa, Ethiopian Federal Democratic Republic of Ethiopia Ministry of Health AND Ethiopian Public Health Association; 2016.

13. Williams B, Mancia G, Spiering W, Agabiti Rosei E, Azizi M, et al. 2018 ESC/ESH Guidelines for the management of arterial hypertension. European Heart Journal. 2018;39(33):1982- 4.

14. World Health Organization W. Chronic diseases and health promotion. STEP wise approach to chronic disease risk factor surveillance (STEPS). . Geneva:World Health Organization. 2010.

15. Getachew F, Dirar A, Solomon D. Prevalence of Undiagnosed Hypertension and Associated Factors among Residents in Gulele Sub-City, Addis Ababa, Ethiopia. J Community Med Health Educ 2018;8(590).

16. Van Minh H, Byass P, Chuc N T K, Wall S. Gender differences in prevalence and socioeconomic determinants of hypertension: findings from the WHO STEPs survey in a rural community of Vietnam. Journal of human hypertension. 2006;20(2):109.

17. Tripathy J P, Thakur J S, Jeet G, Chawla S, Jain S. Alarmingly high prevalence of hypertension and pre-hypertension in North India-results from a large cross-sectional STEPS survey. PloS one. 2017;12(12):e0188619-e.

18. Gudina E K, Bonsa F, Hajito K W. Prevalence of Hypertension and Associated Factors in Bedele Town, Southwest Ethiopia. Ethiopian Journal of Health Sciences. 2014;24(1):21-6.

19. Gebrihet T A, Mesgna K H, Gebregiorgis Y S, Kahsay A B, Weldehaweria N B, et al. Awareness, treatment, and control of hypertension is low among adults in Aksum town, northern Ethiopia: $A$ sequential quantitative-qualitative study. PloS one. 2017;12(5):e0176904-e.

20. Tesfaye F, Byass $P$, Wall S. Population based prevalence of high blood pressure among adults in Addis Ababa: uncovering a silent epidemic. BMC cardiovascular disorders. 2009;9:39.

21. Alemseged F, Haileamlak A, Tegegn A, Tessema F, Woldemichael K, et al. Risk factors for chronic noncommunicable diseases at gilgel gibe field research center, southwest ethiopia: population based study. Ethiopian journal of health sciences. 2012;22(4):19-28.

22. Helelo T P, Gelaw Y A, Adane A A. Prevalence and Associated Factors of Hypertension among Adults in Durame Town, Southern Ethiopia. PLOS ONE. 2014;9(11):e112790.

23. Asresahegn $\mathrm{H}$, Tadesse $F$, Beyene $E$. Prevalence and associated factors of hypertension among adults in Ethiopia: a community based cross-sectional study. BMC Research Notes. 2017;10(1):629.

24. Demisse A G, Greffie E S, Abebe S M, Bulti A B, Alemu S, et al. High burden of hypertension across the age groups among residents of Gondar city in Ethiopia: a population based cross sectional study. BMC Public Health. 2017;17:647.

25. Tesfaye F, Byass $P$, Wall S. High blood pressure among adults in Addis Ababa: a silent epidemic. 2008.

26. Pilakkadavath Z, Shaffi M. Modifiable risk factors of hypertension: A hospital-based case-control study from Kerala, India. Journal of Family Medicine and Primary Care. 2016;5(1):114-9. 
27. Tesfaye F, Byass P, Wall S. High Blood Pressure among Adults in Addis Ababa: a silent epidemic2009. $39 \mathrm{p}$.

28. Chinnakali P, Mohan B, Upadhyay R, Singh A, Srivastava R, et al. Hypertension in the elderly: Prevalence and health seeking behavior. North American Journal of Medical Sciences. 2012;4(11):558-62.

29. Onyango M J, Kombe I, Nyamongo D S, Mwangi M. A study to determine the prevalence and factors associated with hypertension among employees working at a call centre Nairobi Kenya. The Pan African medical journal. 2017;27:178-.

\section{Tables}

Table 1: Socio-demographic characteristics of the study participants among adults in Hawela Tulla Sub-city, Hawassa, southern Ethiopia, 2019.

\begin{tabular}{lrl}
\hline Category & No. (\%) \\
\hline Sex & $187(48.8)$ \\
Male & $196(51.2)$ \\
Female & & \\
Age & $155(40.5)$ \\
18-29 years & $191(49.9)$ \\
$30-49$ years & $37(9.7)$ \\
$\geq 50$ years & \\
Marital status & $320(83.6)$ \\
Married & $44(11.5)$ \\
Single & $14(3.7)$ \\
Divorce & $5(1.3)$ \\
Widow & \\
Address & $125(32.6)$ \\
Urban & $258(67.4)$ \\
Rural & \\
Educational level & $57(14.9)$ \\
No formal education & $578(46.5)$ \\
primary school & 178 \\
High school and above & $148(38.6)$ \\
Occupation & \\
Farmer & $137(35.8)$ \\
Non-employed & $102(26.6)$ \\
Employed & $144(37.6)$ \\
Household income in Ethiopian Birr \\
450 - 1920 & $182(47.5)$ \\
$>1920$ & $201(52.5)$ \\
\hline
\end{tabular}

NB: Employed (government, NGO, Private), Income: based on (HCE, 2016) Exchange rate 1 USD to 29.3673ETB 
Table 2: Daily physical activities among adults in selected house hold at Hawela Tulla Sub-city, Hawassa, southern Ethiopia, 2019.

\begin{tabular}{lccc}
\hline tivities & No & $\mathbf{\leq 1 0} \mathbf{~ m i n}$ & $\mathbf{> 1 0} \mathbf{~ m i n}$ \\
\cline { 2 - 4 } & No. (\%) & No. (\%) & No. (\%) \\
\hline Jrous activities & & & \\
łwing hardwood & $205(53.5)$ & $63(16.4)$ & $115(30.0)$ \\
oughing & $206(53.8)$ & $0(.0)$ & $177(46.2)$ \\
aying football & $357(93.2)$ & $0(.0)$ & $26(6.8)$ \\
eight lifting $(>20 \mathrm{~kg})$ & $324(84.6)$ & $49(12.8)$ & $10(2.6)$ \\
lerate activities & & & \\
ardening & $296(77.3)$ & $67(17.5)$ & $20(5.2)$ \\
ashing clothes by hand, & $281(73.4)$ & $30(7.8)$ & $72(18.8)$ \\
cawing (Fetching) water & $241(62.9)$ & $16(4.2)$ & $126(32.9)$ \\
alking & $0(.0)$ & $102(26.6)$ & $281(73.4)$ \\
ding pedal bicycle & $305(79.6)$ & $27(7.0)$ & $51(13.3)$ \\
\hline
\end{tabular}

Table 3: Bivariable and multivariable logistic regression analysis for prevalence of undiagnosed hypertension among adults in Hawela Tulla Sub-city, Hawassa, south Ethiopia, 2019. 


\begin{tabular}{|c|c|c|c|c|c|}
\hline & Undiagnos & Hypertensio & & & \\
\hline & $\begin{array}{c}\text { Yes } \\
\text { No. (\%] }\end{array}$ & $\begin{array}{c}\text { No } \\
\text { No. (\%) }\end{array}$ & COR $(95 \% \mathrm{CI}]$ & AOR $(95 \% \mathrm{CI}]$ & P-Value \\
\hline : & & & & & \\
\hline Female & $17(8.6)$ & $180(91.4)$ & 1 & 1 & \\
\hline $\begin{array}{l}\text { Male } \\
\text { re in years }\end{array}$ & $30(16.1)$ & $156(83.9)$ & $2.04(1.08,3.83)$ & $3.70(1.64,8.32)$ & $0.002 *$ \\
\hline $18-29$ & $12(7.7)$ & $143(92.3)$ & 1 & 1 & \\
\hline $30-49$ & $28(14.7)$ & $163(85.3)$ & $2.05(1.00,4.174)$ & $2.04(0.89,4.70)$ & 0.093 \\
\hline $\begin{array}{l}50 \text { and above } \\
\text { lucational level }\end{array}$ & 7 (18.9) & $30(81.1)$ & $2.78(1.01,7.65)$ & $2.66(0.82,8.64)$ & 0.105 \\
\hline No formal education & $12(21.1)$ & 45 (78.9) & $2.55(1.10,5.92)$ & $2.50(0.76,8.29)$ & 0.133 \\
\hline srimary school & $21(11.8)$ & $157(88.2)$ & $1.28(0.63,2.62)$ & $1.16(0.44,3.03)$ & 0.766 \\
\hline $\begin{array}{l}\text { Figh school \& above } \\
\text { cupation }\end{array}$ & $14(9.5)$ & $134(90.5)$ & 1 & 1 & \\
\hline Farmer & $12(8.8)$ & $125(91.2)$ & 1 & 1 & \\
\hline Non-employed & $11(10.8)$ & $91(89.2)$ & $1.26(0.53,2.98)$ & $1.18(0.41,3.37)$ & 0.760 \\
\hline Employed & $24(16.7)$ & $120(83.3)$ & $2.08(1.00,4.35)$ & $1.76(0.60,5.20)$ & 0.305 \\
\hline mily history of Hyper & tension & & & & \\
\hline No & $36(10.5)$ & $306(89.5)$ & 1 & 1 & \\
\hline Yes & $11(26.8)$ & $30(73.2)$ & $3.12(1.44,6.75)$ & $3.69(1.31,10.34)$ & $0.014 *$ \\
\hline irrent cigarette smok & ers & & & & \\
\hline No & $43(11.7)$ & $326(88.3)$ & 1 & 1 & \\
\hline $\begin{array}{l}\text { Yes } \\
\text { armful alcohol use }\end{array}$ & $4(28.6)$ & $10(71.4)$ & $3.03(0.91,10.09)$ & $2.19(0.49,9.89)$ & 0.308 \\
\hline No & $35(10.1)$ & 311 (89.9) & 1 & 1 & \\
\hline $\begin{array}{l}\text { Yes } \\
\text { Vsical in }\end{array}$ & $12(32.4)$ & $25(67.6)$ & $4.27(1.97,9.23)$ & $2.62(0.95,7.21)$ & 0.062 \\
\hline No & $18(7.7)$ & $217(92.3)$ & 1 & 1 & \\
\hline Yes & $29(19.6)$ & $119(80.4)$ & $2.94(1.57,5.51)$ & $3.21(1.50,6.84)$ & $0.003^{*}$ \\
\hline ss than five servings & of fruit and & vegetables & $n$ average per day & & \\
\hline No & $42(11.5)$ & 324 (88.5) & 1 & 1 & \\
\hline Yes & $5(29.4)$ & $12(70.6)$ & $3.21(1.08,9.58)$ & $2.58(0.61,10.86)$ & 0.197 \\
\hline insume more salty fo & & & & & \\
\hline No & $5(5.3)$ & $90(94.7)$ & 1 & 1 & \\
\hline Yes & $42(14.6)$ & $246(85.4)$ & $3.07(1.18,8.01)$ & $3.67(1.26,10.64)$ & $0.017 *$ \\
\hline ИI (Kg/m2) & & & & & \\
\hline$<25$ & $27(9.0)$ & $272(91.0)$ & 1 & 1 & \\
\hline 25 and above & $20(23.8)$ & $64(76.2)$ & $3.15(1.66,5.97)$ & $3.06(1.41,6.65)$ & $0.005^{*}$ \\
\hline ek health care for ea & rly sympton & & & & \\
\hline Yes & $11(7.6)$ & $133(92.4)$ & 1 & 1 & \\
\hline No & $36(15.1)$ & $203(84.9)$ & $2.14(1.05,4.36)$ & $4.58(1.85,11.32)$ & $0.001 *$ \\
\hline
\end{tabular}

NB: * statistically significant on multivariate analysis p-value (<0.05), COR: crude odds ratio, AOR: adjusted odds ratio, CI: confidence interval, 1: reference, Un-employed (Self-employed, Merchant, Unemployed (Un/able to work).

\section{Figures}




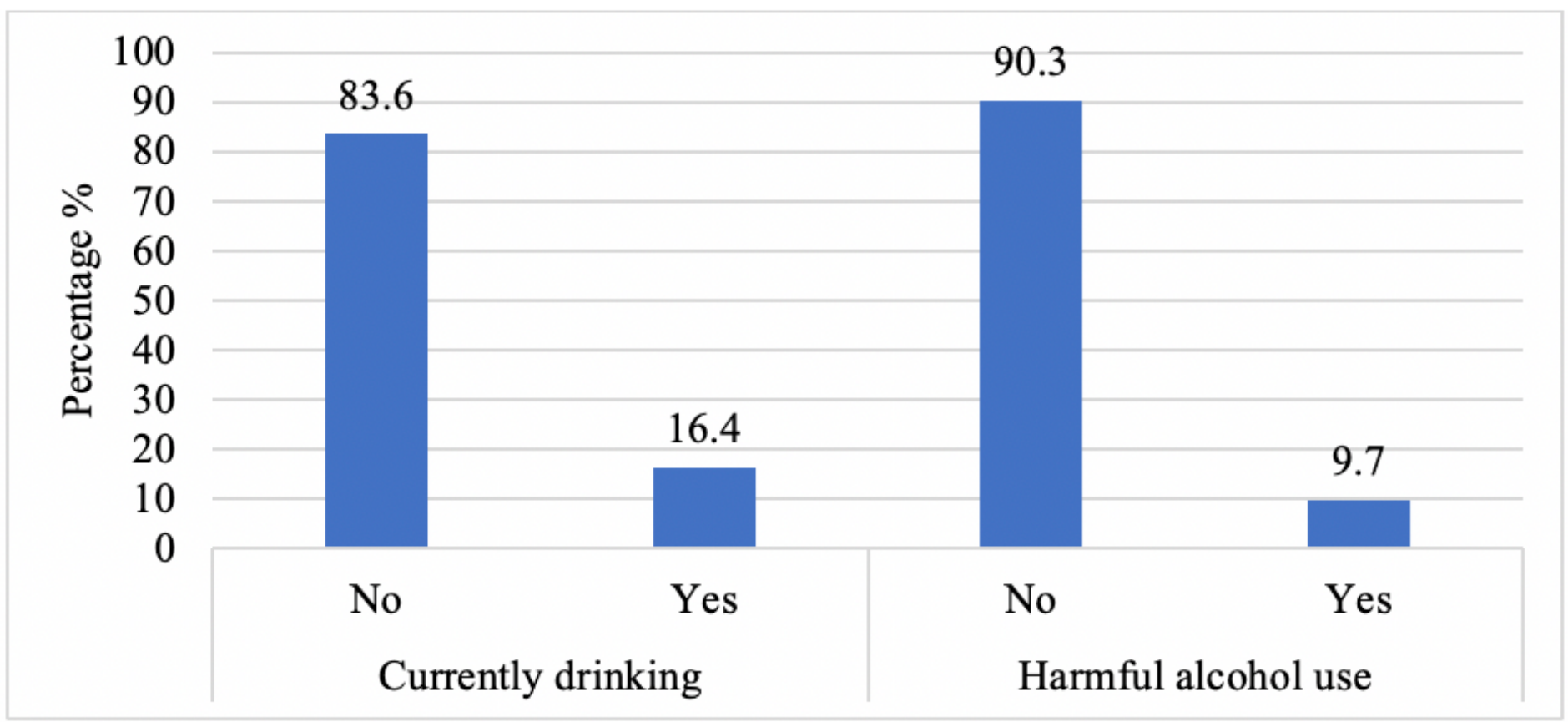

Figure 1

Current and Harmful alcohol use among adults in Hawela Tulla Sub-city, Hawassa, southern Ethiopia, 2019.

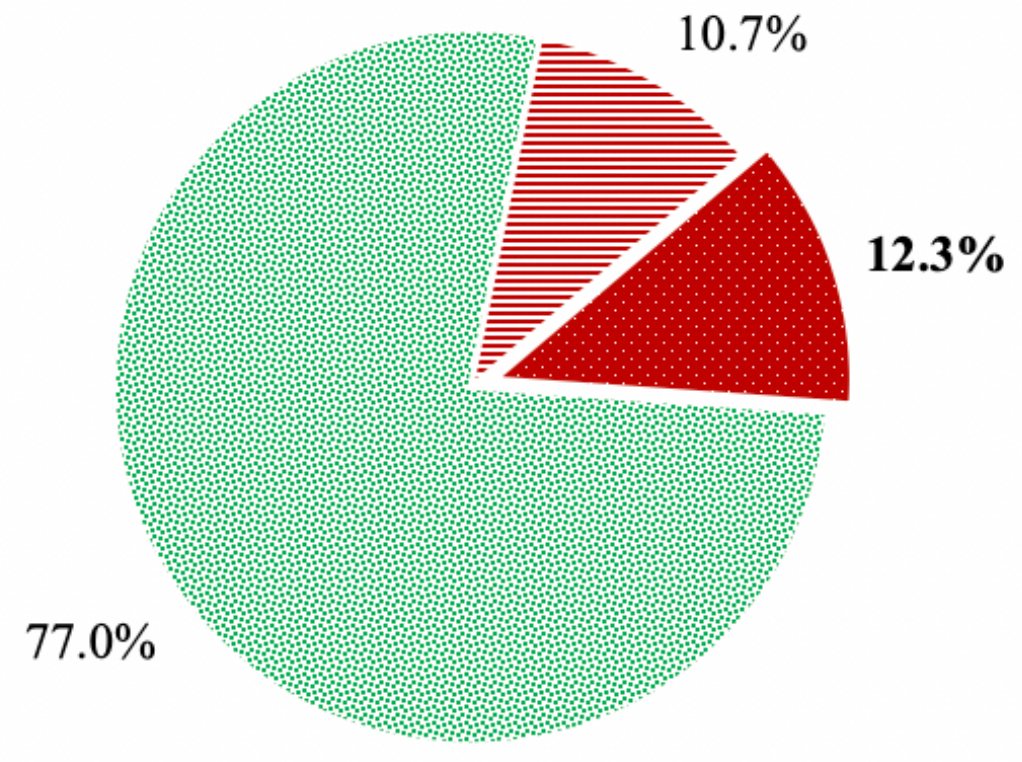

Normal BP

$\equiv$ Prehypertension

aypertension

Figure 2

Prevalence of undiagnosed hypertension among adults in Hawela Tulla Sub-city, Hawassa, southern Ethiopia, 2019. 


\section{Supplementary Files}

This is a list of supplementary files associated with this preprint. Click to download.

- Supplementarymaterials.rar 